\title{
NUEVA RURALIDAD, AGRICULTURA CAMPESINA Y TURISMO RURAL EN ZONAS TURÍSTICAS LACUSTRES DEL SUR DE CHILE. ESTUDIO DE CASO
}

\section{NEW RURALITY, PEASANT AGRICULTURE AND RURAL TOURISM IN LAKE TOURIST AREAS OF SOUTHERN CHILE. CASE STUDY}

Fecha recepción: 7 de septiembre de 2020 / fecha aceptación: 29 de diciembre de 2020

Patricia Castañeda M. ${ }^{1}$ y María Paz Rebolledo C. ${ }^{2}$

Cómo citar este artículo:

Castañeda, P. y Rebolledo, M. P. (2020) Nueva ruralidad, agricultura campesina y turismo rural en zonas turísticas lacustres del sur de Chile. Estudio de caso. Revista Pensamiento y Acción Interdisciplinaria, 6(2), 10-30. http://doi.org/10.29035/pai.6.2.10

\section{Resumen}

El presente artículo tiene por objetivo analizar la dinámica del Turismo Rural desde la perspectiva de la Nueva Ruralidad a través del Estudio de Caso de una localidad campesina de la zona lacustre del sur de Chile. El análisis de las manifestaciones que asume la Nueva Ruralidad en la localidad campesina en estudio, permite constatar transformaciones rurales asociadas a la actividad del turismo estival, complementada con prácticas campesinas agrícolas tradicionales que se mantienen en el tiempo y que aportan la base para la oferta de productos y servicios disponibles, generando nuevos puestos de trabajo acotados y nuevas finalidades a los espacios rurales y a sus actividades distintivas. Asimismo, se observa un respaldo institucional público que acompaña las iniciativas, ampliando las clásicas relaciones focalizadas exclusivamente en la producción agropecuaria, para sumar soportes en la formalización y desarrollo de actividades turísticas familiares factibles de realizar en la agricultura campesina. El caso en estudio permite concluir que las actividades de Turismo Rural realizadas en la localidad desde hace más de cuatro décadas visibilizan nuevos actores rurales, nuevas actividades productivas, revalorizando saberes campesinos que confirman una transformación estructural en plena conformación.

Palabras clave: Agricultura Campesina, Estudio de Caso, Nueva Ruralidad, Turismo Rural, Zonas lacustres del Sur de Chile.

\footnotetext{
1 Chilena. Trabajadora Social y Licenciada en Trabajo Social. Doctora en Ciencias de la Educación. Académica e Investigadora. Escuela de Trabajo Social, Facultad de Ciencias Sociales. Universidad de Valparaíso. Valparaíso, Chile. Correo electrónico: patricia.castaneda@uv.cl

2 Chilena. Ayudante de Investigación. Estudiante Carrera de Periodismo. Facultad de Ciencias Sociales. Universidad de Playa Ancha. Valparaíso, Chile. Correo electrónico: maria.rebolledo@alumnos.upla.cl
} 


\begin{abstract}
The objective of this article is to analyze the dynamics of Rural Tourism from the perspective of New Rurality through the Case Study of a rural twon in the lake área of southern Chile. The analysis of the manifestations assumed by the New Rurality in the peasant town in study, allows to verify rural transformations associated with the activity of summer tourism, complemented with traditional peasant agricultural practices that are maintained over time and that provide the basis for the offer of available products and services, generating new limited jobs and new purposes for ruralareas and their distinctive activities. Likewise, there is a public institutional support that accompanies the initiatives, expanding the classic relationships focused exclusively on agricultural production, to add support in the formalization and development of family tourism activities feasible to carry out in peasant agricultura. The case study allows to conclude that the Rural Tourism activities carried out in the town for more tan four decades make visible news rural actors, new productive activities, revaluing peasantknowledge which confirm a structural transformation in full conformation.
\end{abstract}

Keywords: Case Study, Lake Areas of Southern Chile, New Rurality, Peasant Agriculture, Rural Tourism

\title{
Nueva Ruralidad, Agricultura Campesina y Turismo Rural
}

A partir de la organización temporal de la agricultura chilena aportada por Gómez (1988) se constata que desde el inicio de la Colonia y hasta 1930, la agricultura y la minería fueron la base del desarrollo económico nacional, a partir de un modelo orientado principalmente a la exportación de materias primas. Más tarde, a contar de la gran crisis económica mundial de 1929, se instaló un modelo de desarrollo industrializador sustitutivo de importaciones que focalizó el crecimiento económico en la producción nacional y en la concentración urbana, desplazando el sector rural a un rol proveedor de alimentos para el mercado interno. Entre Agosto de 1962 y Septiembre de 1973 el Estado impulsó cambios estructurales en torno a la propiedad agrícola a través del proceso de Reforma Agraria, acompañado de importantes inversiones en infraestructura, capacitación y transferencia técnica que aportaron a la modernización del agro. Posteriormente, entre 1973 a 1979 la dictadura cívico militar realizó el proceso forzado de Contrarreforma Agraria, liquidando los predios y activos agrícolas entre grupos económicos, empresariado y campesinado. Con este nuevo diseño de propiedad agraria, a partir de la década de 1980 se sentaron las bases para la actual modernización del sector rural chileno, caracterizado por cadenas productivas agroexportadoras, expansión forestal industrial y generación de una estructura de empleo agrícola temporero y mayormente femenino. En este contexto, la agricultura campesina fue desplazada a una posición marginal, con estrategias de producción orientadas principalmente a lógicas de sobrevivencia orientadas al autoconsumo y a la subsistencia.

Según la CEPAL (2019) la noción de Nueva Ruralidad emerge en la década de 1990 a nivel internacional y se fundamenta en las profundas transformaciones asociadas a los procesos de modernización agraria sucedidos a la fecha, destacando 
la importancia creciente de la economía rural no agrícola, la necesidad de superar la dicotomía rural/urbano tradicional, la preocupación por el cuidado del medio ambiente, la evolución de la institucionalidad rural y los cambios respecto de las estrategias de acción realizadas tradicionalmente por el Estado en las áreas rurales. Así, entonces, la Nueva Ruralidad reconsidera a lo rural como problema de estudio, posibilitando el análisis de cadenas productivas, culturas laborales y estructuras económicas en los ámbitos rurales (Rodríguez \& Meneses, 2011). Para C. de Gramont (2008) las principales tendencias que permiten caracterizar a la Nueva Ruralidad corresponden a la desaparición de la definición binaria profundamente diferenciada de campo/ciudad; urbanización del mundo rural, incluyendo ocupaciones del territorio de carácter no agrícolas; creciente presencia de la tecnología, telecomunicación, informática y biotecnología, ocasionando un desarrollo rural asociado a cadenas agroproductivas y producción agrícola industrial de vanguardia; mayor importancia de la población rural no agrícola y de ingresos no agrícolas; expresión de la cuestión campesina a través de los temas de género y pueblos indígenas; y, relevancia del tema medioambiental en el análisis del desarrollo territorial rural. Los enfoques actualmente vigentes en la Nueva Ruralidad se relacionan por una parte con la pluriactividad económica rural en el marco de la globalización y ajustes estructurales derivados de lógicas capitalistas; y por otra, con su definición como una estrategia comunitaria de generación de ingresos de grupos campesinos, que se constituyen en oposición a las lógicas capitalistas (Palafox \& Martínez, 2015).

Kay (2009) asocia la Nueva Ruralidad a cuatro fenómenos sociales que reflejan las transformaciones que se suceden actualmente en los sectores rurales latinoamericanos. El primer fenómeno corresponde a la creciente importancia que ha tomado el desarrollo de actividades económicas extraprediales, las que presentan mayor dinamicidad ymayor productividad, expresándose principalmente en la generación de mejores ingresos que los que producen las actividades agrícolas campesinas tradicionales. Un segundo fenómeno se expresa en la flexibilización y feminización del empleo rural, en donde la creciente producción agroexportadora hortofrutícolas ha creado mayores oportunidades laborales a las mujeres por sus habilidades motoras para trabajar con productos perecederos. Se reconoce que los trabajos femeninos rurales presentan más inestabilidad, peores condiciones laborales en relación a los hombres y existe menos interés en la organización social y en la sindicalización. El tercer fenómeno, corresponde a la creciente interacción entre zonas consideradas tradicionalmente como urbanas y rurales, desdibujando las diferencias entre ambas, dado que por una parte se relocalizan población campesina en zonas urbanas intermedias y, por otra, las zonas rurales avanzan en una acelerada industrialización, acceso a la tecnología y a la urbanización. Un cuarto fenómeno corresponde a la migración internacional latinoamericana, que se expresa con fuerza en las oleadas migratorias estacionales asociadas al empleo agrícola, implicando principalmente a la fuerza de trabajo juvenil. Las remesas generadas por este concepto se destinan preferentemente a consumo, atención médica, educación y mejoras a la vivienda, siendo poco común que se utilicen 
en inversiones productivas en el agro. Como efecto no deseado, se produce una progresiva dependencia a las remesas, bajando la presión por aceptar trabajos por parte de la familia que permanece en la zona de origen migratorio.

Desde la perspectiva de los sujetos sociales, Bengoa (2014) plantea que la Nueva Ruralidad es un concepto que ha desplazado al desarrollo rural como noción previa, visibilizando a dos actores centrales. El primero corresponde a la mujer campesina, reconocida como la mayor fuerza de trabajo rural que sostiene los ciclos de cosecha de la agroindustria latinoamericana, en condiciones de temporalidad y asociada a ciclos migratorios. El segundo grupo corresponde al movimiento indígena como principal demandante del acceso a la tierra, expresado principalmente a través de conflictos asociados a la propiedad de los recursos naturales, contaminación y depredación ambiental. Complementariamente, Pizarro y André (2020) constatan la importancia de los esfuerzos realizados por las agriculturas familiares campesinas en las últimas dos décadas, en torno a la creación de redes alternativas de producción y consumo, con el fin de sostener el tejido sociocultural de las comunidades. Nogar y Capristo (2010) reconocen las expresiones de la Nueva Ruralidad en la reconfiguración de las estructuras productivas, territoriales y poblacionales de los espacios rurales sucedida en las últimas décadas y que han ocasionado por una parte, efectos negativos expresados en despoblamiento territorial, éxodo juvenil, envejecimiento de la población, deterioro ambiental y abandono de cultivos tradicionales; y por otra parte, efectos de transformación asociados a procesos emergentes que visibilizan nuevos actores, nuevas actividades productivas, revalorización de saberes y acciones de innovación agraria. En este contexto, el turismo rural se inscribe en la segunda variante, como una actividad productiva emergente que permite diversificar ingresos y ocupar mano de obra excedente, haciendo posible la participación activa de la población rural, la cohesión interna de una comunidad y la captura de ingresos desde fuera del territorio. Palafox y Martínez (2015) plantean que la Nueva Ruralidad reconoce las crecientes oportunidades que ofrece el entorno rural para la realización de actividades que junto con generar ingresos, permiten conservar el modo y las relaciones de producción enmarcadas en su organización social. En ese marco, el turismo en zonas rurales puede sumarse a las actividades agrícolas campesinas tradicionales de las comunidades, siendo un instrumento de desarrollo rural que permite el aprovechamiento y conservación de los recursos, impulsando una participación comunitaria que fortalece la identidad colectiva local. Esta perspectiva ha sido asumida por el Gobierno de Chile, a través de la Estrategia Nacional de Turismo 2012-2020 (MMA, 2012), publicación oficial que formula orientaciones respecto de la incorporación de la cultura rural, el patrimonio y los pueblos originarios en las nuevas oportunidades que se presentan para el sector en el mediano y largo plazo.

Para el Instituto de Desarrollo Agropecuario INDAP (2020) el turismo rural se caracteriza por desarrollarse en un espacio rural, teniendo como soporte la explotación silvoagropecuaria, con la que se asocian lugares y actividades conexas 
que permiten exponer la cultura y las tradiciones campesinas. Herrera (2009) define el turismo rural como una posibilidad de diversificar las actividades que generan ingresos para quienes habitan el medio rural, especialmente mujeres y jóvenes. Por lo tanto, es clave que cualquier emprendimiento realizado en este contexto tenga impacto efectivo en las familias rurales y en la comunidad local en que se enmarca la iniciativa. Asimismo, el autor ilustra las principales ofertas de actividades del turismo rural, las que corresponden a visitas a áreas silvestres, ecosistemas y observación de flora y fauna; gastronomía regional; senderismo, cabalgatas y cicletadas; visitas a zonas patrimoniales; visitas a actividades productivas tradicionales; práctica de deportes al aire libre; alojamientos y residencias campestres; y eventos culturales, por mencionar las actividades de mayor recurrencia en Chile. Mientras se realizan con una fuerte impronta doméstica y con avances incipientes, son agrupadas en la definición genérica de turismo rural. En la medida que estas actividades escalan, se especializan y generan capitales propios para su desarrollo con mayores rangos de autonomía y perfiles definidos de visitantes, pueden ser reconocidas con mayor detalle como agroturismo, ecoturismo, turismo aventura, turismo cultural, etnoturismo y enoturismo.

Desde una perspectiva instrumental, Varisco (2016) identifica cinco dimensiones del turismo rural, las que corresponden a cultural, económica, social, ambiental y política administrativa. En la dimensión cultural, se relaciona con el patrimonio material e inmaterial, poniendo en valor esos bienes como atractivos turísticos, aportando un proceso de rescate y apreciación de los mismos que fortalece la identidad rural de la población. La dimensión económica a escala local tiene como principal característica la generación de ingresos y de nuevos puestos de trabajo para atender a la demanda, siendo su mejor expresión el trazado de rutas turísticas que permiten configurar una escala de producción basada en la asociación de pequeños y medianos productores. La dimensión social implica la atención en las relaciones de los distintos actores del turismo rural, considerando motivaciones, intereses, niveles de poder y estrategias específicas de cada grupo que forma parte de los eslabones de la ruta turística. En la dimensión ambiental, se plantean beneficios asociados a mantenimiento, conservación y mejora de las zonas naturales; y costos por contaminación, perturbación de flora y fauna y erosión del suelo. La dimensión político administrativa considera fortalecer la diversificación económica; arraigo rural juvenil; revalorización del patrimonio cultural y ambiental; mejoras en la producción y comercialización alimentaria, fomento de la asociatividad y ordenamiento del territorio.

Para Kieffem (2018) la introducción de actividades económicas asociadas al turismo en el territorio rural, modifica las rutinas diarias de la vida campesina y revaloriza sus productos tradicionales frente a un público visitante interesado. Los principales atributos reconocidos en los productos ofrecidos corresponden a ser "originarios del campo, artesanales, naturales, de unidad familiar, esfuerzo, buena salud, tranquilidad, caseros y con identidad cultural" (Köbrich et al., 2014). En este 
contexto, se considera que analizar las iniciativas de turismo rural en el marco de la Nueva Ruralidad es un proceso reflexivo en plena conformación, cuyos resultados pueden aportar a dilucidar los efectos de la urbanización, tecnologización, organización productiva y condiciones laborales contractuales a las que se enfrentan las zonas rurales. Dada la diversidad de sujetos, sistemas productivos y recursos naturales presentes, metodológicamente se observan con interés aquellas investigaciones que permitan revisar las particularidades de la economía rural no agrícola y sus implicancias para los sujetos, territorios e institucionalidad relacionada a estas actividades. Específicamente, las manifestaciones que asume el turismo rural en las zonas lacustres del Sur de Chile resultan de interés para este estudio, dado que presentan actividades económicas rurales que se inscriben en las dinámicas de la Nueva Ruralidad y que son realizadas sobre una amplia base de recursos naturales, económicos, sociales y culturales campesinos, organizados en torno a una oferta turística de alta demanda e interés durante la época estival. Asimismo, se considera la larga data de las actividades turísticas campesinas en las zonas definidas de interés, por lo que aportan caracterizaciones de mayor densidad y especialización que pueden resultar orientadoras para otras localidades turísticas que cuentan con iniciativas de menor desarrollo temporal.

\section{Metodología}

La presente investigación tiene por objetivo analizar la dinámica del turismo rural desde la perspectiva de la Nueva Ruralidad en una localidad campesina de la zona lacustre del sur de Chile. La investigación fue realizada desde el enfoque cualitativo y posee un carácter descriptivo. Para su desarrollo se seleccionó la modalidad de Estudio de Casos, entendida como "una descripción y análisis detallado de unidades sociales o entidades educativas únicas" (Arnal et al., 1992, p. 206-207) que permite describir y analizar situaciones únicas, generar nuevas hipótesis, adquirir conocimientos o diagnosticar en detalle una situación particular. La singularidad del Caso no excluye su complejidad, ya que representa también un examen holista de lo único, lo que significa tener en cuenta las complejidades que lo determinan y definen LACE (1999). Aplicando los referentes de Coller (2000), el caso estudiado corresponde a los siguientes criterios y tipología: según lo que se estudia, corresponde a un caso objeto, que posee fronteras claras y definidas; según su alcance es un caso instrumental que ilustra características que se encuentran presentes en otros casos similares; según la naturaleza del caso es ejemplar, ya que permite ejemplificar el fenómeno en estudio; según el tipo de acontecimiento es contemporáneo o sincrónico, ya que el fenómeno se expresa en el momento en que se desarrolla la investigación; según el uso del caso es exploratorio, ya que su análisis contribuye a construir relevancia del fenómeno; y según el número de casos es único, ya que define un caso ilustrativo singular. A partir de dichos criterios se ha seleccionado como Caso de Estudio la localidad lacustre de Lican Ray a orillas del Lago Calafquén, en la comuna de Villarrica, Región de La Araucanía; debido a que sus características campesinas históricas, económicas, 
culturales, medio ambientales, geográficas, oferta de servicios y conectividad con centros urbanos permiten ilustrar las dinámicas del turismo rural basada en la agricultura campesina características de las zonas lacustres homólogas ubicadas en las regiones de La Araucanía, Los Ríos y Los Lagos. Asimismo, posee desde la década de 1970 una larga experiencia como destino turístico rural, la que se ha mantenido estable a lo largo de los años. Ello permite observar fenómenos de turismo rural con importante densidad en su configuración, ocurrencia y despliegue, aportando nítidas condiciones de contrapuntos con fines de análisis, frente a la emergencia de las dinámicas turísticas contemporáneas.

El levantamiento de información se realizó durante las temporadas estivales y temporadas invernales correspondientes a los años 2018, 2019 y 2020; a partir de las técnicas y estrategias de levantamiento información, las que corresponden a revisión documental, observación no participante y entrevistas semiestructuradas aplicadas a informantes claves, apoyadas en procesos progresivos de acercamiento y establecimiento de relaciones de confianza con dirigentes comunitarios(as), líderes de opinión y vecinos(as) históricos(as) de la localidad. El proceso de análisis tomó como referencia a Simons (2011), identificando las fases de descripción del Caso, análisis conceptual del Caso a partir de los antecedentes aportados en la fase de descripción y la fase de integración y síntesis, que se expresa en el presente artículo en los apartados Discusión de Resultados y Reflexiones Finales. La validación de la información se ha realizado a través de los procedimientos de triangulación de técnicas, de fuentes y de referentes estacionales, observación persistente, descripciones minuciosas e interanálisis.

\section{Resultados}

\section{Descripción del Caso de Estudio. Localidad de Lican Ray}

A partir de información recopilada desde fuentes oficiales y testimonios de informantes claves, puede caracterizarse en términos generales a la localidad de Lican Ray (Flor del Lago en lengua mapuche). Forma parte de la comuna de Villarrica, Región de La Araucanía y está ubicada a $27 \mathrm{~km}$. al sur del centro cívico de la ciudad de Villarrica. Comprende los territorios situados en las laderas norte y oeste del lago Calafquén, limitando al sur y al este con la comuna de Panguipulli. Sus orígenes se encuentran en la respectiva inscripción realizada el año 1944 en el Conservador de Bienes Raíces de Valdivia en beneficio del Fisco, que impulsaba en aquella época la radicación de comunidades mapuche y la colonización chilena y extranjera a título gratuito, con fines de incrementar la explotación maderera, la que se concretó a través de la confección de durmientes desde los bosques nativos existentes, destinados a la Empresa de Ferrocarriles del Estado, asentada transitoriamente en la localidad. Cuando la actividad maderera comenzó a decaer a mediados de la década de 1950, la empresa ferroviaria cesó sus funciones. Más tarde, se evaluó construir una central hidroeléctrica tomando como referencia los 
afluentes del Lago Calafquén, proyectando la inundación de localidad para hacer posible el proyecto, ocasionando la emigración de la casi totalidad de la población original ante dicha noticia. Finalmente, la Central fue construida más al Sur, sobre la base de los afluentes del Lago Pullinque ubicado en la comuna de Panguipulli. La nueva central hidroeléctrica inició sus operaciones en Abril de 1962 (Endesa, 1962). No obstante, a partir del terremoto de 1960 y la erupción volcánica de Marzo de 1964, Lican Ray fue abandonada totalmente, siendo considerada en planes de repoblamiento sólo a contar de la década de 1970. La localidad cuenta con accesos desde Villarrica y Panguipulli, los que fueron asfaltados durante la década de 1990 para mejorar su conectividad.

Actualmente Lican Ray es un destino turístico estacional estival que cuenta con una oferta de playas a orillas del Lago Calafquén, deportes náuticos, acceso a centros termales y a senderos del sector noroeste del Parque Nacional Volcán Villarrica, camping, hospedaje, gastronomía, pesca, senderismo, servicios y comercio ("Turismo. Lican Ray", 2020). Durante la temporada baja (AbrilDiciembre) la localidad cuenta con una población estable de 3.342 habitantes, quienes se concentran territorialmente en la zona urbana intermedia que constituye el pequeño poblado urbano de la localidad, junto con población rural campesina y de ascendencia mapuche que habita regularmente en los predios y en las comunidades indígenas del sector, siendo su principal actividad las faenas productivas agrícolas, pecuarias y forestales campesinas tradicionales, orientadas al autoconsumo y la subsistencia (INE, 2017). Respecto a coberturas de servicios básicos, la localidad cuenta con electricidad y agua potable. Los sistemas de eliminación de excretas y de aguas residuales funcionan en modalidad de fosas sépticas, con el fin de evitar la contaminación del Lago Calafquén. A partir del año 2017 se han realizado importantes obras de pavimentación de calles y pasajes en el radio urbano de la localidad, la que históricamente solo contaba con su avenida principal asfaltada y con veredas para el tránsito peatonal. Asimismo, en los últimos años se han realizado loteos en sectores rurales de la localidad, los que ofrecen parcelas de agrado urbanizadas. En el sector urbano existen segundas viviendas de propiedad de familias que las utilizan en recesos anuales, fines de semana y temporadas de verano, por lo que hay sectores en que las residencias se encuentran desocupadas gran parte del año, quedando las actividades de cuidado de las viviendas y mantención de jardines y áreas verdes a cargo de cuidadores de la localidad. En la temporada alta estival, la localidad puede llegar a bordear las 25.000 personas, las que se hospedan en casas, cabañas, hostales y camping que se ofrecen para arriendo, siendo la mayoría de propiedad de las familias del poblado. El valor del arriendo es variable durante los meses de Enero y Febrero, siendo este último mes el de precios más elevados por existir mayor demanda, y su valor se estima conforme cercanía del hospedaje con las playas, número de días de estadía, número de personas y experiencias favorables de arriendo en ocasiones anteriores con el mismo proveedor. Sus visitantes son preferentemente turistas nacionales, provenientes de las regiones centro sur del país. 
Si bien a la fecha la localidad se ha mantenido como un enclave turístico con una impronta marcadamente campesina e intercultural mapuche; debe declararse que en su entorno directo correspondiente a las comunas de Villarrica, Panguipulli y Pucón, si bien se realizan actividades productivas rurales campesinas homólogas; la diferencia es que dichas actividades comparten el espacio rural con cadenas agroindustriales intermedias, plantaciones forestales, industria láctea y pequeña piscicultura. Del mismo modo, debe mencionarse que en dichas comunas se ha realizado una copiosa inversión en circuitos, servicios y destinos turísticos acreditados a nivel internacional.

\section{Descripción de las Principales Actividades de Turismo Rural en Caso en estudio.}

Las actividades que se realizan en la localidad de Lican Ray conforman una oferta de productos y servicios atractiva para sus visitantes, que distintos tiempos de dedicación e implementación a lo largo del año. No obstante, aún no posee certificaciones ni formalizaciones que permitan definirla con mayor especificidad técnica, por lo que a la fecha se reconoce como una oferta consolidada y diversa que responde al concepto genérico de turismo rural, independientemente del tipo de actividad específica y de la oportunidad en que se lleve a cabo.

\section{a.- Actividades de Turismo Rural que se realizan en temporada alta (verano).}

i) Ferias campesinas. Organizadas en torno a comunidades campesinas aledañas a la localidad de Lican Ray. Se realizan durante una jornada diaria o pueden extenderse por un fin de semana o por ciclos semanales o quincenales. Se localizan en un predio de la misma comunidad anfitriona, por lo general de propiedad de una organización local o de alguna familia participante de la actividad, incorporando señalética para guiar a las personas visitantes a lo largo de los caminos secundarios de acceso. Se distribuye el terreno por sectores para locales de venta, mesas techadas para atención del público, estacionamiento, servicios higiénicos, espacios para actividades recreativas y escenario con amplificación. Por lo general, la oferta se concentra principalmente en gastronomía tradicional campesina de temporada, conservas, repostería y venta de productos de huerta. Las actividades son acompañadas con música tradicional de la zona con reproducciones y música en vivo; juegos campesinos y concursos infantiles. En menor proporción se ofrecen productos hortofrutícolas, miel, artesanías y tejidos. Las actividades funcionan en horarios extendidos desde el mediodía hasta alrededor de las 22 horas. Ejemplos de estas actividades son las Ferias Campesinas realizadas anualmente en los sectores de Melilahuen, Huincacara, Liumalla y en el estadio de la localidad urbana de Lican 
Ray. Las actividades son apoyadas y difundidas por Municipalidad de Villarrica e INDAP.

ii) Muestras Culturales Mapuche. Organizadas en torno a comunidades mapuche, funcionan de manera similar a las ferias campesinas, sumando expresiones de su particular sabiduría ancestral a través de la gastronomía, ceremonias, hierbas medicinales, rogativas, música y relatos distintivos. En ocasiones se construye una ruka o vivienda tradicional, con fines de exposición y enseñanza de la cultura originaria. Puede ilustrarse esta modalidad de Feria a través de la actividad realizada en el sector de Afunalhue, que funciona durante algunos fines de semana de la temporada estival. Las actividades son apoyadas y difundidas por Municipalidad de Villarrica e INDAP.

iii) Ferias de productos hortofrutícolas y de granja. Iniciativas de pequeños campesinos que se organizan para ofrecer sus productos de temporada en ferias o puntos de venta que funcionan diariamente durante toda la temporada estival en diversos lugares estratégicos de la localidad. La venta considera productos generados en huertas e invernaderos cercanos, a los que suman productos adquiridos a proveedores regionales, cuyo origen son los mercados de Temuco, Chillán o de la zona central del país. Ejemplo de esta actividad es la Feria Sausalito de Lican Ray que funciona regularmente hace 46 años, por lo que ha atendido a varias generaciones de visitantes, permitiendo generar relaciones fidelizadas entre feriantes y clientes. Ocupa un recinto en modalidad de comodato, ubicado entre las calles Millañanco esquina Curiñanco, a una cuadra de la avenida principal de la localidad. La organización está constituido por 70 pequeños comerciantes campesinos y de ascendiente mapuche, que realizan venta de productos hortofrutícolas, gastronomía tradicional, árboles ornamentales y frutales, plantas ornamentales, flores, productos apícolas, plantas medicinales, artesanías en madera, cestería y lana, huevos de campo, aves de corral, tortillas de rescoldo, pan amasado, empanadas, leche y quesos. También cuenta con entrega de productos del mar, que son traídos directamente desde la costa de Valdivia. Las actividades son apoyadas y difundidas por la Municipalidad de Villarrica.

iv) Ferias artesanales. Disposición de locales de propiedad municipal o galerías privadas, las que permiten la exposición y venta de artesanías de origen mapuche o campesina elaboradas con materias primas de la zona, principalmente madera nativa, piedra volcánica, lana, orfebrería y textiles. En forma complementaria, se instalan puestos de artesanía con productos provenientes de otras zonas del país. Una de las ferias de mayor trayectoria en este rubro, con más de 25 años de funcionamiento ininterrumpido, corresponde a la Feria Artesanal ubicada entre las calles Cacique Curiñanco y Urbano Tapia, frente a la Plaza de Armas y a un 
costado del Templo Parroquial católico de la localidad. Las actividades son apoyadas y difundidas por la Municipalidad de Villarrica.

v) Visitas campestres. Visitas por el día a predios agrícolas en pleno funcionamiento de actividades propias del verano, asociado principalmente al tiempo de cosechas y guardas para el invierno. Por lo general las visitas contemplan un recorrido por las instalaciones, eventual participación en actividades del campo en huertas, chacras o quintas de frutales, riego, ordeña cuidado de animales menores, almacenamiento en granero, vistas de los paisajes del sector, degustación de almuerzo campestre y rondas de mate. Esta actividad se realiza en algunos predios ubicados en el sector de Challupen Alto, combinando las actividades agrícolas, la gastronomía y las vistas panorámicas al Volcán Villarrica y al Lago Calafquén. Estas visitas aún poseen un carácter informal, siendo difundidas por medio de contactos personales en las ferias campesinas, muestras culturales o ferias hortofrutícolas.

vi) Cabalgatas. Arriendo de caballares para paseos cortos por horas a la localidad y senderos rurales aledaños; o por jornadas para realizar la subida al Volcán Villarrica o visita a escoriales de roca volcánica, producto de grandes erupciones sucedidas en años anteriores. Se pueden contratar los servicios directamente con los propietarios, cuidadores o guías de los caballares en el sector del puente Cariman.

vii) Pesca. Oferta de paseos en lancha o botes a remos con servicio para pesca deportiva en el lago Calafquén. Los servicios se contratan en el sector de los embarcaderos ubicados en la Playa Chica y en la Playa Grande de Lican Ray; o directamente con las personas propietarias de las embarcaciones.

\section{b.- Actividades de Turismo Rural que se realizan en temporada baja (otoño, invierno y primavera).}

i) Ligadas directamente a las tareas de la agricultura campesina, permiten preparar procesos y acopiar productos para comercializar en temporada estival. Entre las principales actividades, se identifican las siguientes. Preparación y manejo de invernaderos para árboles nativos, plantas ornamentales y flores. Siembras hortícolas en invernaderos, chacras y huertas en temporada invernal y primaveral. Poda y manejo de árboles frutales (manzanas, albaricoques, cerezas, ciruelas, duraznos). Recolección de frutos silvestres en época otoñal e invernal para preparación de conservas (Piñones, changles, murta). Manejo apícola según temporada. Manufactura de artesanías. Tallado en madera. Recolección de fibras vegetales para manufactura de cestería y teñido de lanas. Hilandería. Tejidos. Telares. Faenas de reproducción, engorda y cruce de ganado bovino para productos lácteos y quesería. Faenas 
de reproducción y engorda de ganado menor para oferta de carne. Faenas de reproducción y crianza de aves de corral para oferta de carne y huevos de campo.

Mantención de gallineros. Cuidado y cruza de caballares. Mantención de caballerizas.

ii) Ligadas a infraestructura y puestos de venta. Mantención y reparaciones de locales de venta e infraestructura de ferias costumbristas, encuentros culturales mapuche, ferias hortofrutícolas y ferias artesanales. Mantención de botes de pesca y embarcaciones menores. Tramitación de permisos sanitarios. Tramitación de permisos municipales.

iii) Actividades complementarias. Manejo de jardines y cercos de segundas viviendas de la localidad. Mantención de segundas viviendas de la localidad.

\section{Análisis conceptual de las Condiciones de Nueva Ruralidad en el Turismo Rural en Caso en Estudio, desde la perspectiva de los fenómenos sociales asociados.}

Tomando como referencia los fenómenos sociales asociados a la Nueva Ruralidad propuestos por Kay (2009), pueden observarse las siguientes características presentes en el Caso de estudio.

Crecienteimportancia del desarrollo deactividadeseconómicasextraprediales. La información disponible confirma que las actividades extraprediales realizadas en la temporada estival alcanzan mayor dinamicidad, con ocasión del alto flujo de veraneantes que recibe la localidad y que amplifica ostensiblemente la demanda por los productos locales. Respecto la mayor productividad y generación de mejores ingresos que los que producen las actividades agrícolas tradicionales, es posible observar esta condición en la medida que las ofertas consolidadas en ferias y puntos de venta permiten ajustar precios y rangos de ganancia sobre los productos, los que no son posibles de replicar en temporada baja por escasez de compradores. Estas actividades generan nuevos puestos de trabajo estacionales, convocando un flujo de ingresos de reporte diario y de mayor cuantía, debido a la complementariedad que alcanzan con las actividades agrícolas estacionales que se realizan en forma simultánea.

Flexibilización y feminización del empleo rural. Las actividades de turismo rural descritas han generado mayores oportunidades laborales de las mujeres campesinas, en la medida que la demanda por gastronomía tradicional campesina de temporada, productos hortofrutícolas y artesanías convoca directamente con los saberes campesinos femeninos que se revalorizan debido a la alta demanda que reciben por quienes visitan la localidad durante los períodos estivales. Por lo general, las mujeres campesinas poseen una fuerte presencia en las 
organizaciones comunitarias vecinales y de población mayor, las que impulsan actividades de turismo rural. Sin embargo, por lo general las mujeres tienden a ocupar preferentemente cargos como socias y en ocasiones excepcionales cargos directivos, lo que confirma su menor interés en la organización social y en la sindicalización.

Creciente interacción entre zonas urbanas y rurales. A pesar de que el turismo rural tiene a la base actividades campesinas tradicionales, el acceso a la tecnología y a la urbanización son características que alcanzan una mayor presencia en la dinámica del turismo rural. El uso de teléfonos móviles para contactos y confirmaciones de servicios, la gestión de oferta de productos por internet o redes sociales, la transferencia electrónica como medio de pago o los registros audiovisuales de las actividades de turismo rural a través de soportes de telefonía o cámaras especializadas, representan algunos ejemplos vinculados al uso de la tecnología como medio de interacción urbano rural que exigen coberturas eficientes de red de internet en la localidad como requisito operacional orientado a optimizar la gestión del turismo rural. Complementariamente, en temporada estival la localidad cuenta con centros para conexión a internet, servicios de compañías telefónicas móviles y servicio de cajero automático. Respecto a la urbanización, el cumplimiento de estándares sanitarios básicos en todos los servicios y productos ofrecidos debe ser garantizado por autorizaciones transitorias o permanentes de las respectivas autoridades sanitarias, siendo evidencia que no se plantean distinciones entre zonas urbanas y rurales para la entrega de las respectivas certificaciones.

Migración internacional. Este fenómeno es de reciente data, estimándose su presencia actualmente en el $1,1 \%$ de la población regional (INE, 2017). En la localidad la presencia de migración internacional preferentemente latinoamericana muestra una inserción laboral en torno a actividades de servicio con baja calificación.

Análisis conceptual de las Condiciones de Nueva Ruralidad en el Turismo Rural en Caso en Estudio, desde la perspectiva de los sujetos sociales.

A partir de la perspectiva de los sujetos sociales de la Nueva Ruralidad planteados por Bengoa (2014) o Pizarro y André (2020), pueden realizarse las siguientes precisiones.

Mujer campesina. Las actividades revisadas, visibilizan a la mujer rural como la principal fuerza de trabajo que sostiene las actividades vinculadas al turismo rural en condiciones de temporalidad estival. Su aporte en saberes tradicionales de gastronomía, manejo de huertas familiares, crianza de aves de corral, ordeña y quesería, técnicas de conservería, amasandería y manufactura de artesanías, resultan centrales para la confección y mantención de la oferta de servicios y productos que se realiza en la localidad. Por oposición, las actividades 
tradicionalmente masculinas ocupan un rol secundario en el turismo rural, asociados a tareas específicas que requieren vigor físico y habilidades para desplazarse en espacios abiertos, tales como trabajo agrícola, pesca y cabalgata.

Movimiento indígena. En el marco de una comuna con un $26.97 \%$ de población de ascendiente indígena (INE; 2017), las actividades estivales reflejan dicha condición a través de la abierta expresión de la cultura mapuche y sus manifestaciones asociadas a la vida campesina se presentan en forma diferenciada en la oferta de turismo rural de Lican Ray. Las demandas por mejores condiciones de vida material, acceso a recursos naturales y manifestaciones por las legítimas reivindicaciones históricas encuentran en las ferias culturales mapuche renovadas oportunidades de expresarse y difundirse en públicos urbanos, no siempre informados con detalle de las dinámicas de conflicto actualmente en curso.

Redes alternativas de producción y consumo. Sostener una oferta de servicios y productos a lo largo de la temporada estival es un importante desafío para quienes realizan turismo rural, debido a que su capital inicial es acotado y sus tiempos dedicados a la actividad deben ser compatibilizados con las tareas agrícolas propias de los tiempos de cosecha y guarda. Lo anterior genera el desafío de contar con redes de trabajo a nivel comunitario, que permitan alternar tareas y contar con apoyos suficientes para responder a los objetivos planteados. En este sentido, debe plantearse que este componente de trabajo en red es aún incipiente, ya que se apoya preferentemente en las redes familiares, vecinales y de amistad, enfrentando el desafío de construir confianzas más amplias para respaldar la constitución de nuevas redes que posean mayor especialización y cobertura en los temas claves de la dinámica turística estival. Los avances en estas acciones son apoyadas directamente por el municipio local y SERCOTEC de la Región de la Araucanía.

Complementariamente, puede mencionarse el fenómeno de envejecimiento de la población campesina y despoblamiento del territorio rural como consecuencia de la permanente migración de la población juvenil a zonas urbanas por razones de estudio y trabajo, lo que se refleja actualmente en que a nivel regional, la población rural que alcanza el $28 \%$ proyectándose a la baja para los próximos años (INE, 2017).

\section{Análisis de las dimensiones del Turismo Rural en Caso en Estudio.}

A partir de la propuesta de dimensiones de turismo rural planteada por Varisco (2016), pueden realizar las siguientes consideraciones.

Dimensión cultural. La localidad en estudio posee una diversidad intercultural expresada a través de las culturas campesina tradicional y campesina mapuche. Ambas improntas aportan características específicas respecto de conocimientos y prácticas intergeneracionales o ancestrales que agregan valor a las manifestaciones 
o recreaciones de las mismas, fortaleciendo la identidad local. Sin embargo, debe tenerse presente que el rescate y fortalecimiento de las expresiones culturales locales se enfrentan a una potencial sobreexposición instrumental con fines mercantiles, implicando el riesgo de la pérdida de sus sentidos más profundos y trascendentes.

Dimensión económica: Las actividades de turismo rural realizadas en la localidad han aportado a la generación de ingresos independientes a las tareas agrícolas tradicionales, ampliando cada año el número de iniciativas y personas participantes. Con ello, se han generado nuevos puestos de trabajo estacionales que permiten atender a la creciente demanda de productos y servicios turísticos rurales ofrecidos. Sin embargo, las experiencias realizadas a la fecha demuestran que el trazado de rutas turísticas o la organización de una escala de producción basada en la asociación de pequeños y medianos productores es aún una tarea pendiente, debido a las dificultades vinculadas a disposición de mayor volumen de capital, manejo técnico avanzado y madurez organizacional, que aporten mayores respaldo a estas aspiraciones.

Dimensión social: Las relaciones de los distintos actores vinculados a la actividad de turismo rural de la localidad demuestra que persiste un importante nivel de atomización en la organización social, que se apoya centralmente en relaciones familísticas o vecinales de larga data, ralentizando la inclusión de nuevos actores e iniciativas en el corto plazo. Asimismo, se observa una clara diferenciación entre las actividades de carácter campesino tradicional y las de carácter campesino mapuche, que rigidiza las oportunidades de ampliar las bases de colaboración entre las diversas organizaciones.

Dimensión ambiental. Las actividades de turismo rural realizadas en la localidad se inscriben en las características de degradación del uso del suelo propias de la agricultura familiar campesina que realiza una ocupación intensiva de los recursos disponibles. Asimismo, se observan efectos negativos derivados de la sobrepoblación estival, expresada principalmente en aumento de los residuos y basuras, junto con la contaminación del aire por emisiones de monóxido de carbono e hidrocarburos por aumento del parque automotriz y del lago por residuos de hidrocarburos emitidos por las embarcaciones a motor. Los aspectos ambientales positivos que pueden destacarse están asociados a la calidad del paisaje rural, con existencia de bosque nativo y cursos de agua limpios que acercan a los visitantes al contacto con la naturaleza y a los beneficios de la vida al aire libre.

Dimensión político administrativa. La localidad de Lican Ray convoca el apoyo de diversas instituciones para el desarrollo de iniciativas de turismo rural, destacando principalmente la Municipalidad de Villarrica, el Instituto Nacional de Desarrollo Agropecuario INDAP y el Servicio Nacional de Turismo SERNATUR. Estos esfuerzos buscan una mejor proyección de retención juvenil rural y de tasa de retorno post finalización de estudios superiores, debido a la creciente demanda 
de servicios turísticos de la zona y en un ordenamiento territorial que considera incipiente el resguardo de sus principales atractivos turísticos de la contaminación o de la expansión inmobiliaria. El mayor desafío actual se focaliza en mejorar la calidad de servicios entregados a la población visitante y la búsqueda de alternativas que permitan romper la rígida estacionalidad de la demanda turística que afecta a la localidad, la que pudiera activarse cuando la localidad cuente con conectividad expedita al sector noreste del Volcán Villarrica, lo que permitiría su articulación a la temporada alta de nieve y deportes invernales.

\section{Discusión de los Resultados}

El análisis de las manifestaciones que asume la Nueva Ruralidad en la localidad caso de estudio, permite constatar transformaciones rurales asociadas a la actividad del turismo estival, complementada con prácticas campesinas agrícolas tradicionales que se mantienen en el tiempo y que aportan la base para la oferta de productos y servicios disponibles, generando nuevos puestos de trabajo acotados y nuevas finalidades a los espacios rurales y a sus actividades distintivas. Asimismo, se observa un respaldo institucional público que acompaña las iniciativas, ampliando las clásicas relaciones focalizadas exclusivamente en la producción agropecuaria, para sumar soportes en la formalización y desarrollo de actividades turísticas familiares factibles de realizar en la agricultura campesina. No obstante considerar positivamente los aprendizajes comunitarios obtenidos a la fecha, la conformación exitosa de cadenas productivas en torno al turismo rural no alcanzan aún en la localidad los niveles de formalización que les permitan ser reconocidas como rutas oficiales. Actualmente se encuentran en niveles de asociatividad parciales que se activan generalmente frente a contingencias, en una dinámica de colaboración específica y focalizada.

En relación a los sujetos asociados a las actividades de turismo rural, se confirma la presencia de mujeres e integrantes de pueblos indígenas como sus principales responsables. En este sentido, la progresiva pérdida de población juvenil de las zonas rurales focaliza una doble responsabilidad en las mujeres campesinas, ya que por una parte son las depositarias de las tradiciones gastronómicas, artesanales y de actividades de huerta, cuidado de aves y crianza de animales menores que se encuentran a la base de su oferta; pero por otra, son reconocidas como la piedra angular de las relaciones familiares, comunitarias y de fidelización de sus visitantes. Su trayectoria personal les ha permitido manejar con destreza ambas dimensiones, pero requieren mayor apoyo intergeneracional para llevar a cabo las actividades turísticas cotidianas y para proyectar los aprendizajes obtenidos y consolidar la posición de destino turístico campesino de la localidad. En el caso de las actividades llevadas a cabo con impronta mapuche, en términos operativos debe manifestarse que dichas familias se reconocen portadoras de la misma cultura campesina característica de la zona, siendo intencionados los aspectos relacionados con lengua, artesanía y religiosidad para explicitar sus 
particularidades. Lo anterior devela una coexistencia campesina tradicional y campesina mapuche en el territorio, que ha generado relaciones interétnicas distintivas y colaborativas que contribuyen a aportar mayor densidad a la oferta turística local y a la identidad de la localidad y que tienen el potencial de profundizarse en el futuro próximo, apoyándose recíprocamente.

A lo largo de los años, el turismo rural estival de la localidad se ha masificado, demandando estabilidad y continuidad en la entrega de sus productos y servicios. Lo anterior ha generado una creciente influencia en las actividades agrícolas que deben realizarse en temporadas de otoño, invierno y primavera. Inicialmente estas tareas fueron concebidas con un carácter secundario o complementario dado que la capacidad de respuesta históricamente instalada había permitido acoger favorablemente la creciente demanda estival. Sin embargo, en la última década las familias campesinas de la localidad se han visto en ocasiones sobrepasadas por la demanda, por lo que actualmente dedican mayor parte de su tiempo alterno disponible en la preparación de los insumos, consecución de materias primas y manejo de ciclos de producción, con el fin de anticiparse y responder adecuadamente a las fechas en que se realizarán mayores solicitudes de productos y servicios, formalizando así su preocupación por contar con existencias suficientes para enfrentar la demanda de sus visitantes en temporada alta. En la medida que esta situación se incrementa, puede afirmarse que en forma indirecta opera como un factor protector para la mantención de prácticas agrícolas, artesanales y gastronómicas tradicionales a lo largo del tiempo, visibilizando y valorizando la historia del producto en todas las etapas de su manufactura. Asimismo, el manejo avanzado de dichas prácticas sienta las bases para la búsqueda de modalidades de ejecución que impulsen rangos de innovación o adecuación en el desarrollo de las actividades agrícolas, trayendo en consecuencia mejoras en la calidad de los servicios. Asimismo, concretiza progresivamente la promesa de generación de nuevos puestos de trabajo estacionales e ingresos frescos complementarios a la actividad agrícola tradicional.

En una visión de mayor alcance, debe declararse que el turismo rural no se enfrenta directamente en la misma localidad estudiada con cadenas productivas agroindustriales o con expansión forestal industrial. Sin embargo, debe considerarse que este tipo de actividades que están presentes en un perímetro de mayor amplitud, siendo observables a nivel comunal, provincial, regional e interregional. Lo anterior distingue a la localidad como enclave de turismo rural que se ha mantenido a lo largo del tiempo, siendo valorada permanentemente por sus visitantes a partir de su condición de contraste respecto de los procesos de transformaciones rurales de mayor complejidad que desplazan a la población campesina de sus localizaciones históricas originarias y alteran en forma severa los ecosistemas en que se insertan. También se rescata la identidad de turismo rural basada en una impronta campesina y mapuche ancestralmente contenida en el territorio, que coexiste con ofertas de turismo internacional existentes en sus áreas de influencia aledañas, realizando importantes aportes de contrapunto 
con las condiciones de homogeneización derivadas de los actuales procesos de globalización en curso.

\section{Reflexiones Finales}

Teniendo presente que la modernización agraria chilena desplazó a la agricultura campesina a una posición marginal orientada principalmente por lógicas de sobrevivencia; el turismo rural puede ser concebido como la puesta en valor de los retazos de una cultura campesina tradicional que aún lucha por mantenerse vigente, enfrentándose al peligro de perder en el mediano plazo sus bases de reproducción agroecológicas y demográficas. La nueva ruralidad ha ajustado progresivamente sus dinámicas desde su amplio acceso y manejo de los territorios y los capitales, redefiniendo cadenas productivas, culturas laborales y estructuras económicas en los ámbitos agrarios, conforme sus necesidades orientadas principalmente al mercado externo. Como contraparte, las opciones de turismo rural posibles de implementar en las economías campesinas de la zona lacustre del sur de Chile se configuran como estrategias comunitarias para la generación de ingresos de familias rurales, en una posición de clara oposición a las lógicas capitalistas de acumulación de capital, siendo capaces de articularse desde los márgenes del sistema en plena conformidad con su histórica cultura de sobrevivencia.

En consecuencia, los resultados obtenidos de la investigación realizada constatan que el Caso en estudio confirma la presencia de la dinámica de la Nueva Ruralidad, expresado en un territorio rural urbanizado y conectado que desdibuja sus fronteras clásicas con el mundo urbano y en donde la cuestión campesina se expresa principalmente a través de los temas de género y pueblos indígenas. Asimismo, la localidad se instala en la intersección entre los enfoques vigentes de Nueva Ruralidad, ya que por una parte expresa pluriactividad económica rural que compatibiliza el turismo con la producción agrícola tradicional; y por otra, evidencia la existencia de estrategias comunitarias de generación de ingresos para grupos campesinos. El Caso en estudio permite concluir que las actividades de turismo rural realizadas en la localidad desde hace más de cuatro décadas visibilizan nuevos actores rurales, nuevas actividades productivas y revalorización de saberes campesinos, que confirman una transformación estructural en plena conformación. 
Nueva ruralidad, agricultura campesina y turismo rural en zonas turísticas lacustres del sur de Chile.

\section{Referencias bibliográficas}

Arnal, J., del Rincón D., \& Latorre, A. (1992). Investigación Educativa. Barcelona: Labor

Bengoa, J. (2014) ¿Fin del desarrollo rural? Revista ALASRU 10, 87-105. Recuperado de https://www.alasru.org/pdf/REVISTA10Alasru.pdf

CEPAL (2019) Nuevas narrativasparauna transformación ruralen América Latina yEl Caribe. La nueva ruralidad. Conceptos y Medición. Ciudad de México: Naciones Unidas/CEPAL. Recuperado de https://repositorio.cepal.org/bitstream/ handle/11362/44665/S1900508_es.pdf?sequence=4\&isAllowed=y

Carton de Grammont, H. (2008) El concepto de nueva ruralidad. En E. Pérez, M. Farah \& H. C de Grammont (Comp.) La Nueva Ruralidad en América Latina. Avances Teóricos y Evidencias Empíricas. Bogotá. Ed. Pontificia Universidad Javeriana, Consejo Latinoamericano de Ciencias Sociales CLACSO.

Coller, X. (2000) Estudios de Caso. Cuadernos Metodológicos № 30. Madrid: Centro de Investigaciones Sociológicas.

ENDESA (1962) Sistema Hidroeléctrico Pullinque. Santiago de Chile. Empresa Nacional de Electricidad Sociedad Anónima. Recuperado de http://www. memoriachilena.gob.cl/archivos2/pdfs/MC0037322.pdf

Gómez, S. (1988) La Agricultura chilena. Las dos caras de la modernización. Santiago de Chile: FLACSO AGRARIA. Recuperado de http://flacsochile.org/ biblioteca/pub/publicos/1988/libro/000041.pdf

Kieffem,M.(2018).Conceptosclavesparaelestudio delTurismo RuralComunitario.El periplo sustentable, (34), 8-43. Recuperado de http://www.scielo.org.mx/ scielo.php?script=sci_arttext\&pid=S1870-90362018000100008\&lng=es\&tln $\mathrm{g}=\mathrm{es}$.

Herrera, R (2009). Estudio sobre turismo rural en Chile. Valdivia: Instituto Interamericano de Cooperación para la Agricultura IICA. Recuperado de http://mastor.cl/blog/wp-content/uploads/2018/07/Herrera.-Turismo-Ruralen-Chile.-Valdivia.-2009.-133-pgs.pdf

INDAP (2020) Programa de Desarrollo Rural. Santiago de Chile: INDAP Ministerio de Agricultura. Recuperado de http://www.indap.gob.cl/te-recomendamos/ turismo-rural/programa-turismo-rural

INE (2017) Resultados del Censo de Población y Vivienda. Región de la Araucanía. Santiago de Chile. Instituto Nacional de Estadísticas. 
Kay, C. (2009). Estudios rurales en América Latina en el periodo de globalización neoliberal: ¿una nueva ruralidad? Revista mexicana de sociología, 71(4), 607-645. Recuperado de http://www.scielo.org.mx/scielo.php?script=sci_ arttext\&pid=S0188-25032009000400001\&lng=es\&tIng=es.

Köbrich, C., Bravo, F., Sáez, L., \& Boza, S. (2014). Estudio para un sello de productos y servicios de la agricultura familiar campesina. Santiago de Chile: Oficina de Estudios y Políticas Agrarias ODEPA. Recuperado de https://www.odepa.gob. cl/wp-content/uploads/2014/12/selloProductosServiciosAFC.pdf

Laboratorio para el Análisis del Cambio Educativo (LACE). (1999) Introducción al Estudio de Caso en Educación. Cádiz: Universidad de Cádiz.

Ministerio del Medio Ambiente (2012) Chile. Estrategia Nacional de Turismo 20122020. Recuperado de https://mma.gob.cl/wp-content/uploads/2014/10/1_ Estrategia-Nacional-de-Turismo-2012-2020.pdf

Nogar, G., \& Capristo, V. (2010) Nuevos escenarios para los espacios rurales. El turismo rural como proceso emergente. En Nogar G. y Jacinto G. (2010) (Comp.) Los espacios rurales. Aproximaciones teóricas y procesos de intervención en turismo rural. Buenos Aires: La Colmena.

Palafox, A., \& Martínez, M. (2015) Turismo y nueva ruralidad. Camino a la sustentabilidad social. Revista Latinoamericana de Estudios Socioambientales Letras Verdes (18), 137- 158. http://dx.doi.org/10.17141/ letrasverdes.18.2015.1608

Pizarro, E., \& André, P. (2020) Movimientos sociales, políticas públicas y construcción de mercados para las agriculturas familiares campesinas en Chile. Revista ALASRU, 5(9) 1-32. Recuperado de http://www.ceil-conicet. gov.ar/ojs/index.php/revistaalasru/article/view/617/554

Rodríguez, A., \& Meneses J. (2011). Transformaciones rurales en América Latina y sus relaciones con la población rural. Reunión de Expertos sobre Población Territorio y Desarrollo Sostenible. Santiago, 16-17 de agosto. Santiago: Comisión Económica para América Latina y el Caribe (CEPAL).

Simons, H. (2011) El Estudio de caso: Teoría y Práctica. Madrid: Morata.

Varisco, C. (2016) Turismo Rural. Enfoque metodológico para un enfoque sistémico. Pasos. Revista de Turismo y Patrimonio Cultural, 14(1), 153-167. http://doi.org/10.25145/j.pasos.2016.14.010 
Nueva ruralidad, agricultura campesina y turismo rural en zonas turísticas lacustres del sur de Chile. Estudio de caso por Patricia Castañeda y María Paz Rebolledo

\section{Sitios Web}

Villarraica (2020). Visit Villarrica. Recuperado de https://www.visitvillarrica.cl

Dirección de correspondencia:

Patricio Castañeda

Contacto: patricia.castaneda@uv.cl 